\title{
RESENHA Umbigos enterrados: corpo, pessoa e identidade \\ Capuxu através da infância
}
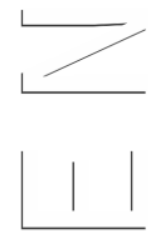

Fabrício Marcelo Vijjales ${ }^{1}$

Pontifícia Universidade Católica do Rio Grande do Sul

SOUSA, Emilene Leite de. Umbigos enterrados: corpo, pessoa e identidade Capuxu através da infância. Florianópolis: Editora da UFSC, 2017. 397 p. 
$\mathrm{O}$ livro de Emilene Leite de Sousa apresenta a pessoa Capuxu. Está fundamentado na etnologia indígena, dialogando com a antropologia da criança, do campesinato e com as discussões sobre etnicidade. Trata-se assim, de uma etnografia da construção da pessoa em aspectos distintos. $\mathrm{O}$ eixo central do livro é a criança camponesa Capuxu e tudo o que gira em seu entorno, as noções de identidade, a aprendizagem, o trabalho, dieta alimentar específica, nominação, sistemas de parentesco e apadrinhamento e aprendizado. Todos esses aspectos são examinados para discussões sobre corpo, infância e identidade.

No primeiro capítulo, a autora apresenta sua entrada em campo. Ao mesmo tempo, todo o suporte teórico e os recursos que encontrou na coleta de dados. Emilene afirma que o corpo da criança camponesa Capuxu é a chave de acesso para a investigação das noções de produção da pessoa e corporalidade em seu livro. As inquietações de pesquisa são nomeadas cuidadosamente por meio da percepção e da observação etnográfica, especificando os procedimentos metodológicos.

O segundo capítulo apresenta o povo Capuxu através da identidade. Como característico, a endogamia está estreitamente relacionada com a territorialidade. A autora foca no sentimento de pertencimento, peculiar ao povo Capuxu, o que desponta a viabilidade de análise através da investigação dos marcadores sociais. A identidade desponta com uma linguagem própria, por meio da qual o povo Capuxu representa a si mesmo. Embora seu foco não seja a identidade em específico, ela representa um invólucro da produção do corpo, objetivo da pesquisa. A produção da fronteira e o sentimento de pertença servem de guia na elucidação da fabricação do corporalidade Capuxu.

Segundo a autora, há um desígnio de que o parentesco está fortemente ligado com a identidade, bem como os traços em comum servem de sinal da perpetuação da comunidade Capuxu. Desde a infância, a produção da identidade repousa na delimitação de fronteiras e pelo reconhecimento de outsiders (povos que residem em sítios vizinhos), cujo hábito campesino Capuxu se diferencia. A análise demonstrou que a construção da identidade passa por sinais diacríticos evocados pelo grupo e vai sendo produzida desde a infância. As categorias são analisadas nos demais capítulos.

No capítulo 3 é apresentada a definição de campesinato. O texto apresenta a condição camponesa como forma de organização social e do cultivo da terra no Sítio de Santana de Queimadas, descrito pelas crianças. O foco principal do capítulo é a descrição das dimensões simbólicas que o Sítio representa. Desse ponto, espaço, território e territorialidade são categorias imprescindíveis para dar conta das representações e apropriações do povo Capuxu a respeito do lugar onde habitam.

O ambiente da morada, o local do trabalho e as estradas do Sítio camponês evidenciam pela forma de organização uma vigilância exercida pelos moradores. Os espaços extrapolam as barreias físicas da morada Capuxu e se estendem por um complexo de espaços habitados pelos membros da família e por animais domésticos. A criança é inserida nesses espaços desde muito pequena, levada por seus familiares enquanto trabalham na terra. Na medida em que cresce a criança 
vai participando das tarefas como forma de treinamento do corpo para o trabalho que é próprio ao campesinato.

No capítulo 4 a pesquisadora estabelece uma relação entre o sistema de parentesco. O estudo do nome próprio e o apadrinhamento como formas de produção do corpo estabelecendo elos familiares que reforçam a autonomia da criança são examinados. Da mesma forma, o parentesco revela o modo como as relações sociais são fortalecidas. Embora o sistema não obrigue o casamento entre primos, esse sistema torna comum a disposição para a criança aceitar o casamento no futuro. Embora territorialidade tenha importância no estabelecimento do parentesco, a migração de alguns membros não quebra o vínculo de parentesco fortemente estabelecido.

A autora entende parentesco Capuxu num amplo sentido, referindo os laços de sangue (consanguinidade) e de afinidade (casamento). O sangue é importante marcador das relações de parentesco Capuxu, da formação da identidade e das relações de parentesco. Os efeitos genéticos, que são produto da endogamia, são sentidos por consequência e alguns casos são evidenciados. Doenças como a esclerose precoce é o resultado da intensa mistura de sangue que o casamento entre primos pode provocar. Embora presente a genética, os efeitos do casamento são abordados pelo viés das representações que o povo Capuxu constrói sobre a doença. Os mais jovens têm consciência do problema, no entanto não vislumbram a possibilidade de casamento fora do grupo. Se por um lado, tais representações são encaradas de forma diferente pelos jovens, por outro lado, os mais velhos ignoram o problema.

$\mathrm{O}$ ato de nomear é importante momento na produção da pessoa e conduziu Emilene à hipótese de que não se trata de uma simples designação, mas sim, parte do possuidor como um pedaço idêntico a ele, inseparável da pessoa ao nomear. Quanto ao sobrenome todos são designados Capuxu. Por vezes o nome próprio é transmitido dentro do próprio grupo, em alguns casos são trazidos de fora do grupo. Nome, pessoa e identidade, além da territorialidade compreende uma relação entre si. Da mesma forma, serve como fator de expansão, individuação e diferenciação.

O apadrinhamento é um importante mecanismo na construção dos sistemas de parentesco. Repleto de rituais de relação, o sistema de dar, receber e retribuir pela relação que se estabelece com a criança, a família e os padrinhos é uma forma de reforçar o vínculo. $\mathrm{O}$ apadrinhamento, que pode ser no ato do batismo ou mesmo por escolha das crianças forma uma aliança muito forte que permite multiplicar as redes interpessoais.

O capítulo 5 adentra na construção da pessoa e a infância Capuxu. Inaugura o capítulo a apresentação da infância para a antropologia e os estudos até então realizados. Emilene considera que a criança deve ser considerada como sujeito relativamente autônomo com modo próprio de se apropriar do mundo e experimentá-lo. E ainda, que é portadora de grande valor para manutenção e reprodução sociocultural. Na mesma linha, a produção da infância por meio da fabricação dos corpos passa por compreender o lugar da criança nessa cultura.

A infância da criança Capuxu em sua vivência e cultura é essencialmente camponesa. As particularidades mais relevantes da infância Capuxu repousam sobre a organização econômica, social e de parentesco. As primeiras relações da criança são estabelecidas com os animais. Consequentemente, o contato através da fala e do toque é estabelecido como meio de comunicação. No entanto, a relação mais importante é estabelecida com a figura feminina. A socialização é firmada por meio de regras e determinada pelas mulheres. Apesar da constante vigilância 
salta aos olhos a autonomia da criança camponesa. Todo o sítio é frequentado pelas crianças Capuxu e o ambiente é o invólucro da infância camponesa.

O capítulo contextualiza o trabalho como destaque na infância pela ênfase no processo econômico e social da comunidade. O trabalho para a criança Capuxu ganha sentido na medida em que são inseridos na lida agrícola. Ainda que seja informada com caráter lúdico, a criança se considera trabalhadora ainda que inserida gradativamente nas tarefas domésticas no âmbito de casa e seus arredores.

Compreende ainda o universo infantil Capuxu a existência do corpo e da alma, dimensões indissociáveis. Esta experiência vivida pela comunidade essencialmente católica e religiosa é mantida por meio de temeridades mobilizadas pela produção de malassombros. O imaginário infantil é representado por figuras e lendas relacionadas com a cultura da qual fazem parte. Fato é que essa temeridade servirá de treinamento para o desenvolvimento da coragem da criança Capuxu, o que será levado para o resto de sua vida.

No capítulo 6, é apresentada a produção da pessoa Capuxu por meio da fabricação do corpo na infância. Estudo que encontra fundamento nas reflexões acerca da pessoa e da corporalidade em sociedades indígenas tornando possível pensar as sociedades camponesas e étnicas no Brasil. Os processos de produção do corpo da criança são apresentados por Emilene a partir de uma distinção entre processo de produção do corpo de processos de cura do corpo.

Para a autora as técnicas corporais estão relacionadas ao trabalho, ao nado, ao umbigo, aos dentes cabelos e unhas. Estas dinâmicas objetivam a busca por um corpo saudável. A cura busca o reequilíbrio de um corpo que saiu da sua ordem natural. De acordo com a autora, a produção do corpo passa pela necessidade de produzir o corpo e inicia ainda antes do nascimento. A menstruação, momento em que a menina Capuxu se torna "mocinha", representa uma forma pela qual tudo que é impuro é expelido do corpo. Outro ponto importante é a gravidez, rito carregado de preparativos e planejamento. O filho é esperado e desejado. As práticas que são feitas durante a relação sexual estão relacionadas com a fecundação do óvulo. Os ritos são formalizados até o parto que tem procedimento bem específico.

Ao recém-nascido é despendido cuidado seguindo as observações de semelhanças com os pais, cuidados com a cabeça da criança. O umbigo demanda processos mais longos de cuidados. $\mathrm{O}$ enterro do umbigo representa os processos de produção do corpo da criança através das simbologias e concretiza-se como expressão mais forte da indissociabilidade que a pessoa Capuxu estabelece com a terra, traçando assim o destino da criança.

O momento da amamentação é marcado por toques e cuidados da mãe pela serenidade e calmaria. Há uma forma de classificar a infância Capuxu por meio de fronteiras estabelecidas pela faixa etária. A formação dos primeiros dentes é uma característica importante na formação do corpo pela evidência de que o corpo se forma da maneira esperada.

A observação de Emilene enfatiza que a infância Capuxu é caracterizada por uma riqueza de técnicas corporais aprendidas desde tenra idade. Passa por observação e vivências de técnicas comuns na infância Capuxu. Técnicas que além de representar conhecimentos úteis à vida no campo objetivam produzir corpos habilitados para isso. Ser Capuxu é estar imerso em uma gama de representações a respeito do corpo e da alma, da saúde e da doença, que termina por assumir técnicas peculiares para garantir o funcionamento saudável do corpo e da alma e constituir uma formação harmoniosa da pessoa. 
Nessa direção, a autora levanta a questão do conhecimento e os processos nativos de aprendizagem na infância Capuxu privilegiando a aprendizagem não escolar. O conhecimento infantil é estabelecido pela experiência no seio da comunidade e tem relação com o ambiente e com as pessoas. O processo de conhecimento é analisado como importante ferramenta para a produção do corpo, principalmente por estar vinculada ao trabalho, utilização de linguagens infantis, do vestuário.

A alimentação é fonte importante na produção do corpo tendo em vista a exigência da vida sertaneja. Os cuidados com o corpo descrevem, assim, o processo de fabricação do corpo da criança Capuxu como um modo de produzir a pessoa. A relação do corpo com a terra, para os Capuxu na terra do Sítio de SantanaQueimadas, é boa porque é forte. A melhor maneira de lidar com a terra é possuir um corpo forte. A produção do corpo da criança Capuxu faz parte de um amplo processo de elaboração da pessoa e está atrelado e fundamentado ao ethos camponês que desemboca na fabricação da identidade coletiva.

No livro, entre as possibilidades metodológicas utilizadas para a concretização dos objetivos propostos destacam-se a coleta de desenhos e histórias elaboradas pelas crianças. Os registros escritos e a observação ressaltam a ação de ouvir as crianças como sujeitos ativos, como produtores de sua cultura e da autonomia do universo infantil. Isso tudo, permite entender como os Capuxu vivenciam sua infância e são coadjuvantes na formação do próprio corpo.

Por fim, a autora esclarece que o arsenal teórico permitiu lançar luz sobre todo o empreendimento proposto no livro: o de investigar a produção da pessoa Capuxu a partir da fabricação de corpos na infância. Certamente, o livro traz contribuição significativa acerca das ideias e concepções sobre a infância, consolidando um campo de pesquisa de grande relevância na construção da investigação tendo como protagonista a criança campesina. 
Estes e outros livros da Coleção Brasil Plural, da Editora da UFSC e do INCT Brasil Plural, podem ser acessados no endereço:

https://brasilplural.paginas.ufsc.br/colecao-brasilplural/
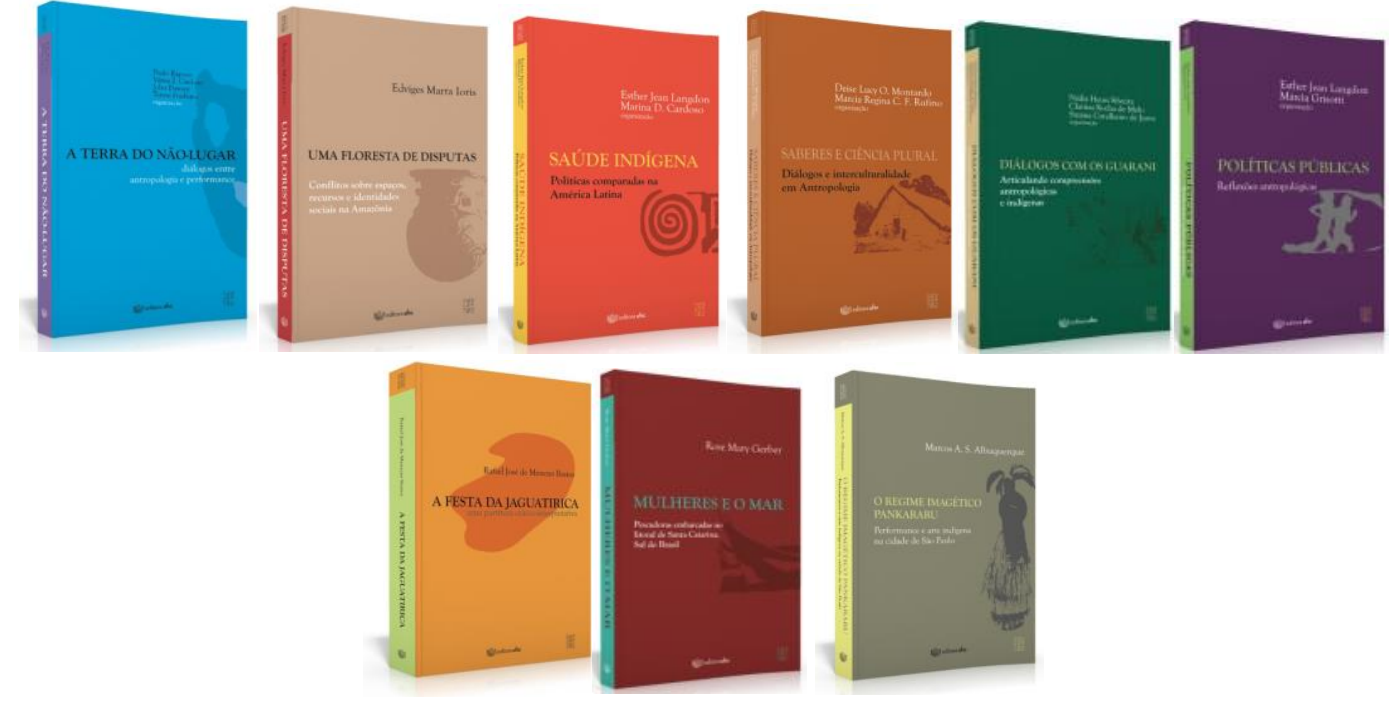